\title{
Determinants of respiratory symptoms in insulation workers exposed to asbestos and synthetic mineral fibres
}

\author{
P ERNST, S SHAPIRO, R E DALES, MARGARET R BECKLAKE
}

From the Department of Epidemiology and Biostatistics, McGill University, and the Respiratory Division, Department of Medicine, Montreal General Hospital, Montreal, Quebec, Canada

ABSTRACT The determinants of respiratory symptoms were studied in an active workforce of insu $\stackrel{\mathbb{1}}{?}$ lation workers exposed to asbestos and synthetic mineral fibres. Responses to a mailed respiratory symptom questionnaire from 537 insulation workers without diagnosed asbestosis were analysed $\mathcal{C}_{0}$ using logistic regression. Wheezing complaints and breathlessness were related primarily to currento cigarette smoking and to symptoms suggesting an asthmatic predisposition antedating work in the trade. There was also evidence that these complaints were related to occupational exposure(estimated by number of hours worked in the trade) in subjects with prior airways hyperreactivity. $\frac{\mathbb{R}}{8}$ An asthmatic predisposition antedating work in the trade was the major determinant of acute respiratory symptoms in the workplace. The effects of workplace exposures on respiratory symptoms may have been underestimated due to selective withdrawal from the active workforce $-\frac{\bullet}{\bullet}$ and due to inaccuracies in the measure of exposure used.

The increase in morbidity and mortality due to chronic obstructive lung disease continues to be an issue of widespread general concern. ${ }^{1}$ Environmental and host factors have been implicated in its causation. Among the former, cigarette smoking is the most important. ${ }^{1}$ Only a minority of smokers, however, develop significant airflow limitation despite equivalent amounts smoked. ${ }^{2}$ According to the Dutch hypothesis, an asthmatic predisposition is also an important determinant of chronic airway disease and the role of hyperreactivity of the airways has been identified as the central question today in the epidemiology of chronic airways obstruction. ${ }^{3}$ There is also gathering evidence that occupational exposures to dust and fumes are associated with an increased risk of developing this syndrome. ${ }^{45}$ For coal mining ${ }^{4}$ and certain hardrock mining exposures, ${ }^{5}$ the association is sufficiently strong to be considered causal.

The relation between exposure to working environments contaminated by asbestos dust and airway abnormality remains controversial. ${ }^{6}$ Airflow limitation is common among asbestos workers ${ }^{7}$ and mild degrees of airways obstruction have been found even in the absence of smoking. ${ }^{8}$ Many of these environments are dusty - for example, the insulation trade, in

Accepted 13 May 1986 which exposure to asbestos fibres and more recen to synthetic mineral fibres has traditionally been heavy. The present report describes the results of a\% respiratory symptom questionnaire survey carried out $\stackrel{\mathbb{Q}}{2}$ among insulation workers as a preliminary to study- $\overrightarrow{\overrightarrow{0}}$ ing their lung function and airway reactivity. The 3 questionnaire responses were used to determine? whether workplace exposures are an independent risk: factor for chronic respiratory symptoms and whethero the effect of this exposure is greater in those subjects $\stackrel{\Phi}{3}$ with an asthmatic predisposition. We were also inter-o ested in whether such an asthmatic predisposition 3 . might be a determinant of acute respiratory symp-ò toms experienced at work.

\section{Methods}

WOR KFOR CE

The workforce selected for the present study com- $N$ prised all insulators working in Quebec in 1982 whon were members of local 58 of the International Associ-N ation of Heat and Frost Insulators and Asbestos ${ }_{\sigma}^{\omega}$ Workers. This union local represents $95 \%$ of all insulators employed in the construction industry in Quebec. Identification of the population was carried out $\stackrel{D}{\$}$ by a cross reference of names present both on a union ${ }_{7}^{+}$ membership list and on a list supplied by the Office de 
la Construction du Quebec (OCQ). This records the number of hours a year worked by each insulator in Quebec for the purpose of calculating pension benefits and controlling work permits. The target population thus defined included 644 subjects who were alive at the time of the start of the study (January 1983). Of the 644 subjects, 558 returned their questionnaire giving a response rate of $87 \%$. Twenty one subjects were not considered further because they were receiving compensation for asbestosis, leaving 537 in the analysis.

\section{MEASUREMENT TOOL}

The measurement tool used was a shortened version of the standard ATS-DLD respiratory symptom questionnaire $^{9}$ sent by mail and self completed; 517 subjects returned the French version, 20 a similar English version. The questionnaire contained all the original questions concerning the presence and severity of the four basic respiratory symptoms-cough, phlegm, dyspnoea, and wheeze; all questions concerning cigarette smoking; and all questions pertaining to past respiratory illness or atopy. Questions were added concerning symptoms occurring in relation to workplace exposures, history of atopy or respiratory illness in natural children, and symptoms of chronic rhinitis. Questions concerning the year of first employment in the trade and the number and length of times a subject worked as a insulator outside Quebec were also included.

\section{RES PIRATORY SYMPTOMS}

The respiratory symptoms chosen for analysis as dependent variables are defined in table 1 . The complaints of "wheeze apart from colds" and "dyspnoea grade 2" were considered a priori to be the principal outcomes of interest since they were thought to reflect

Table 1 Definition of respiratory symptoms used as outcome variables

\begin{tabular}{ll}
\hline Symptom & Positive answer to \\
\hline $\begin{array}{l}\text { Wheeze apart } \\
\text { from colds }\end{array}$ & $\begin{array}{l}\text { Does your chest ever sound wheezy or } \\
\text { whistling apart from colds? } \\
\text { Porsistent wheeze } \\
\text { whistling most of the time? }\end{array}$ \\
Dyspnoea grade 2 & $\begin{array}{l}\text { Do you have to walk more slowly than } \\
\text { people your own age on the level because } \\
\text { of breathlessness? }\end{array}$ \\
Dyspnoea grade 3 & $\begin{array}{l}\text { Do you ever have to stop for breath when } \\
\text { walking at your own pace on the level? } \\
\text { Do you usually cough on most days for } 3 \\
\text { consecutive months or more during the } \\
\text { year? }\end{array}$ \\
Chronic cough & $\begin{array}{c}\text { Doun usually bring up phlegm from your } \\
\text { chest on most days for } 3 \text { consecutive } \\
\text { months or more during the year? }\end{array}$ \\
Symptoms at work & $\begin{array}{c}\text { Two of cough, wheeze, and dyspnoea while } \\
\text { working in a dusty environment }\end{array}$ \\
\hline
\end{tabular}

airway status and expected to be of sufficient frequency and to represent significant abnormality. The report of respiratory "symptoms at work" was examined because of the postulated relation to an asthmatic predisposition. "Chronic cough" and "chronic phlegm" were included for descriptive purposes. "Persistent wheeze" was included as a dependent variable after examining symptom prevalence according to the different categories of smoking (current smokers, never smokers, other smokers) (see table 2). The strong association between the complaint of "persistent wheeze" and current smoking gave validity to this symptom as a reflection of airway abnormality.

\section{BRONCHIAL REACTIVITY SCALE}

In an effort to quantify each subject's asthmatic predisposition a scale representing bronchial activity was derived by assigning different weights to questions thought to reflect hyperreactivity of airways present before employment as an insulator. The pertinent questions and their respective weights are listed in table 3 . The weights were chosen empirically to reflect both the presumed severity of airway hyperreactivity and the likelihood that such a history would be associated with asthma and therefore the degree to which it reflected an asthmatic predisposition. Thus the largest relative weight was given to (1) history of attacks of wheezing with shortness of breath before employment suggesting the presence of asthma, and (2) the diagnosis of asthma by a doctor during childhood or adolescence. It was argued that since most subjects started their trade in their late teens or early $20 \mathrm{~s}$, such a history suggested prior airway hyperreactivity. Wheezing or a diagnosis of chronic bronchitis at a young age was also thought to be suggestive of an asthmatic predisposition but it was thought that in such cases bronchial lability would be less than that found in frank asthma or with airway obstruction severe enough to cause shortness of breath. A history of hay fever, eczema, urticaria, chronic rhinitis, or positive allergic skin tests is found more often among asthmatic than non-asthmatic subjects and has been shown to be associated with a greater mean airway reactivity. This association, however, is inconsistent, and there is considerable overlap in the frequency distribution of bronchial lability directly measured in such individuals and that of non-atopic individuals. ${ }^{10}$ Therefore the relative weight given to positive answers to these questions was less. A history of atopy, asthma, or chronic bronchitis in a subject's natural parents or children suggests a genetic predisposition to asthma. Since this refers to a generation removed from the subject, however, the assigned weight was less than such a history given by the subject himself. The weights given for each positive 
Table 2 Symptom prevalence (\%) by age group and smoking category

\begin{tabular}{|c|c|c|c|c|c|c|c|c|c|c|c|c|}
\hline \multirow{2}{*}{$\begin{array}{l}\text { Age group (years) } \\
\text { Smoking category } \\
\text { No }\end{array}$} & \multicolumn{4}{|c|}{$17-34$} & \multicolumn{4}{|c|}{$35-50$} & \multicolumn{4}{|c|}{$51-68$} \\
\hline & $\begin{array}{l}S \\
116\end{array}$ & $\begin{array}{l}N S \\
40\end{array}$ & $\begin{array}{l}\text { Other } \\
42\end{array}$ & $\begin{array}{l}\text { All } \\
198\end{array}$ & $\begin{array}{l}S \\
148\end{array}$ & $\begin{array}{l}N S \\
32\end{array}$ & $\begin{array}{l}\text { Other } \\
89\end{array}$ & $\begin{array}{l}\text { All } \\
269\end{array}$ & $\begin{array}{l}S \\
30\end{array}$ & $\begin{array}{l}N S \\
10\end{array}$ & $\begin{array}{l}\text { Other } \\
30\end{array}$ & $\begin{array}{l}\text { All } \\
70\end{array}$ \\
\hline $\begin{array}{l}\text { Symptoms: } \\
\text { Wheeze apart from colds } \\
\text { Persistent wheeze } \\
\text { Dyspnoea grade } 2 \\
\text { Dyspnoea grade } 3 \\
\text { Chronic cough } \\
\text { Chronic phlegm }\end{array}$ & $\begin{array}{r}33 \cdot 6 \\
11 \cdot 2 \\
5 \cdot 2 \\
2 \cdot 6 \\
31 \cdot 9 \\
43 \cdot 1\end{array}$ & $\begin{array}{r}5 \cdot 0 \\
0 \\
2 \cdot 5 \\
2 \cdot 5 \\
7 \cdot 5 \\
15 \cdot 0\end{array}$ & $\begin{array}{r}11 \cdot 9 \\
4 \cdot 8 \\
4 \cdot 8 \\
0 \\
7 \cdot 1 \\
21 \cdot 4\end{array}$ & $\begin{array}{r}23 \cdot 2 \\
7 \cdot 6 \\
4 \cdot 6 \\
2 \cdot 0 \\
21 \cdot 7 \\
32 \cdot 8\end{array}$ & $\begin{array}{l}44 \cdot 6 \\
25 \cdot 0 \\
20 \cdot 3 \\
13 \cdot 5 \\
46 \cdot 6 \\
54 \cdot 1\end{array}$ & $\begin{array}{c}21 \cdot 9 \\
0 \\
15 \cdot 6 \\
12 \cdot 5 \\
9 \cdot 4 \\
21 \cdot 9\end{array}$ & $\begin{array}{l}25 \cdot 8 \\
11 \cdot 2 \\
12 \cdot 4 \\
10 \cdot 1 \\
14 \cdot 6 \\
29 \cdot 2\end{array}$ & $\begin{array}{l}35 \cdot 7 \\
17 \cdot 5 \\
17 \cdot 1 \\
12 \cdot 3 \\
31 \cdot 6 \\
42 \cdot 0\end{array}$ & $\begin{array}{l}50 \cdot 0 \\
43 \cdot 3 \\
40 \cdot 0 \\
10 \cdot 0 \\
46 \cdot 7 \\
53 \cdot 3\end{array}$ & $\begin{array}{c}50 \cdot 0 \\
0 \\
60 \cdot 0 \\
30 \cdot 0 \\
20 \cdot 0 \\
30 \cdot 0\end{array}$ & $\begin{array}{l}30 \cdot 0 \\
20 \cdot 0 \\
20 \cdot 0 \\
13 \cdot 3 \\
13 \cdot 3 \\
20 \cdot 0\end{array}$ & $\begin{array}{l}41 \cdot 4 \\
27 \cdot 1 \\
34 \cdot 3 \\
14 \cdot 3 \\
28 \cdot 6 \\
35 \cdot 7\end{array}$ \\
\hline
\end{tabular}

$\mathrm{S}=$ Current smokers; NS = never smoked as much as one cigarette a day for a year; Other = includes ex-smokers, pipe, and cigar smokers:

Table 3 Components of the reactivity scale

\begin{tabular}{|c|c|c|c|}
\hline Description & Prevalence & Relative weight & \\
\hline \multicolumn{4}{|l|}{ Wheezing syndromes before employment: } \\
\hline 1 Episodes of wheezing with dyspnoea present & $6 / 537$ & 6 & \\
\hline 2 Asthma present & $13 / 537$ & 6 & \\
\hline 3 Any wheezing present & $47 / 537$ & 4 & \\
\hline 4 Chronic bronchitis present & $15 / 537$ & 4 & \\
\hline \multicolumn{4}{|l|}{ Personal history of atopy: } \\
\hline 5 Hay fever & $37 / 537$ & 2 & \\
\hline 6 Eczema & $22 / 537$ & 2 & \\
\hline 7 Urticaria & $18 / 537$ & 2 & \\
\hline 8 Positive allergic skin test & $37 / 537$ & 2 & \\
\hline 9 Nose blocked for 3 months or more of the year (chronic rhinitis) & $165 / 537$ & 2 & \\
\hline \multicolumn{4}{|l|}{ Family history of atopy or wheezing syndromes: } \\
\hline 10 Parental history of chronic bronchitis & $53 / 537$ & 1 & \\
\hline 11 Parental history of asthma & $43 / 537$ & 1 & 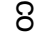 \\
\hline 12 Parental history of eczema & $33 / 537$ & 1 & 응 \\
\hline 13 Parental history of urticaria & $13 / 537$ & 1 & $\underline{\underline{z}}$ \\
\hline 14 Parental history of hay fever & $21 / 537$ & 1 & बे \\
\hline 15 Asthma in subjects' children & $24 / 537$ & 1 & $\overline{7}$ \\
\hline 16 Hay fever in subjects' children & $31 / 537$ & 1 & + \\
\hline 17 Urticaria in subjects' children & $9 / 537$ & 1 & \\
\hline 18 Eczema in subjects' children & $31 / 537$ & 1 & \\
\hline 19 Chronic bronchitis in subjects' children & $18 / 537$ & 1 & \\
\hline
\end{tabular}

answer were then cumulated for each individual to calculate his total hyperreactivity score. These total scores had a theoretical range of 0 to 40 . The distribution of actual scores was skewed towards zero with $71 \cdot 1 \%$ of the respondents having a total score of 2 or less.

\section{MEASURE OF EXPOSURE}

Insulators in Quebec are employed through a union hiring hall which assigns the work from about 200 different employers. Many of these firms are small and as a result hygiene surveys were most often unavailable. Accordingly the estimate of exposure to dust and mineral fibre was based on the duration of exposure only. This information was gathered from three sources. Firstly, we obtained the total number of hours worked by each subject from 1963 to 1983 from the OCQ (referred to above). Secondly, 150 hours was added for each month worked outside Quebec using information reported on the question- naire. Thirdly, for subjects whose first employment in the trade dated before 1963, an estimate of prior exposure was obtained by multiplying the mean annual hours of work from 1963 to 1983 by the num-? ber of years worked as an insulator before 1963. The cumulative exposure was thus expressed as totali hours worked in the trade.

ANAL YSES

Logistic regression was applied to model the associ $\frac{7}{8}$ ation between the outcomes of interest and the poten tial risk factors. The principal models were construc N ted using the Generalised Linear Interactive Modelling (GLIM) system. ${ }^{11}$ Secondary analyses too determine which components of the reactivity scalew were responsible for its predictive power were pero formed using the Statistical Analysis Systems (SAS) logistic regression procedure. ${ }^{12}$ This permitted the evaluation of the individual items in each of the three components of the score: wheezing syndromes before 
employment; personal history of atopy; and family history of atopy and wheezing syndromes.

\section{Results}

Descriptive information including the distribution of subjects as to age and smoking category is shown in table 2. Most subjects were aged under 51 and most were current smokers $(294 / 537,54 \cdot 7 \%)$. A smaller number of non-smokers $(82 / 537,15 \cdot 3 \%)$ and the remaining category $(161 / 537,30.0 \%)$ included exsmokers and current pipe and cigar smokers. Within each age category symptoms were more common in smokers than in non-smokers; the exceptions were for the symptoms of wheeze and dyspnoea in the subjects aged over 50. In general, rates in the category which included ex-smokers as well as pipe and cigar smokers were intermediate between smokers and nonsmokers.

The results obtained from the logistic regression analysis on all 537 subjects are shown in table 4 . The odds ratios approximate the relative risks associated with a difference of one unit of measurement for each of the risk factors considered (smoking, reactivity score before employment and occupational exposure) conditional on the others in the model remaining fixed. Thus compared with never smokers, current smokers had an increased risk of developing all the respiratory symptoms examined except dyspnoea. Current smokers were more than three times as likely as non-smokers to complain of wheeze apart from colds, whereas the complaint of persistent wheezing was also strongly associated with current smoking; the complete absence of this symptom in subjects who had never smoked as much as one cigarette a day for a year (never smokers) precludes accurate estimation of the odds ratio. For chronic cough, chronic phlegm, and acute symptoms at work, the increase in risk among current smokers compared with never smokers was of the order of six, four, and twofold respectively. As regards the reactivity score before employment, each unit increase in the score was associated with an increase in the risk of wheeze apart from colds by a factor of 1.16 and the risk of acute respiratory symptoms during dusty work by a factor of 1.28. As regards occupational exposure, expressed in units of 1000 hours of work, this did not appear to affect the risk of developing most respiratory symptoms after accounting for age, smoking, and prior airway reactivity. A small decrease in the risk of dyspnoea grade 2 was found with increasing exposure. The interpretation of this negative effect in the presence of a statistically significant interaction between exposure and reactivity is difficult, however. The presence of a positive interaction between exposure and reactivity suggests a small increase in risk with exposure in those subjects with more evidence for an asthmatic predisposition. Interaction terms between exposure and smoking category, and smoking category and reactivity, did not contribute significantly to the prediction of any of the respiratory symptoms.

A similar analysis, but restricted to current smokers, is shown in table 5. The analysis was carried out for two reasons: firstly, to search for a dose response between the presence of respiratory symptoms and amount smoked and, secondly, in an attempt to discover a relation between symptoms and other risk factors which might be masked by the strong association between symptoms, especially the wheezing syndromes, and smoking category. No dose response relation could be shown between the amount smoked (in units of 10 pack years of cigarette consumption) and the frequency of current respiratory symptoms. The reactivity score was again a significant predictor of both grades of wheezing. There was, however, a significant relation between exposure and persistent wheeze with an increase in the risk of persistent wheeze by a factor of 1.06 for each

Table 4 Odds ratios and 95\% confidence intervals (in parentheses) for all 537 subjects

\begin{tabular}{|c|c|c|c|c|}
\hline \multirow[b]{2}{*}{ Symptoms } & \multicolumn{4}{|l|}{ Risk factors } \\
\hline & $\begin{array}{l}\text { Smoking category: } \\
\text { current smokers } \\
v \text { never smokers }\end{array}$ & $\begin{array}{l}\text { Reactivity score } \\
\text { (per unit on scale) }\end{array}$ & $\begin{array}{l}\text { Exposure } \\
\text { (per } 1000 \text { hours) }\end{array}$ & $\begin{array}{l}\text { Exposure reactivity } \\
\text { interaction }\end{array}$ \\
\hline $\begin{array}{l}\text { Wheeze apart from colds } \\
\text { Persistent wheeze } \\
\text { Dyspnoea grade } 2 \\
\text { Chronic cough } \\
\text { Chronic phlegm } \\
\text { Symptoms at work }\end{array}$ & 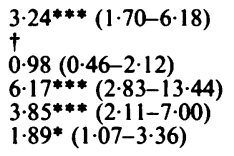 & $\begin{array}{l}1 \cdot 16^{* * *}(1 \cdot 08-1 \cdot 23) \\
1 \cdot 17^{* * *}(1 \cdot 08-1 \cdot 27) \\
1 \cdot 22^{* * *}(1 \cdot 13-1 \cdot 33) \\
1 \cdot 13^{* * *}(1 \cdot 05-1 \cdot 20) \\
1 \cdot 10^{* *}(1 \cdot 03-1 \cdot 17) \\
1 \cdot 28^{* * *}(1 \cdot 18-1 \cdot 38)\end{array}$ & $\begin{array}{l}1.000(0.96-1.03) \\
1.02(0.96-1.07) \\
0.90 *(0.85-0.95) \\
1.00(0.96-1.04) \\
0.99(0.96-1.03) \\
1.01(0.97-1.04)\end{array}$ & $\begin{array}{l}\overline{1.01} *(1.00-1.03) \\
1.01 *(1.00-1.02) \\
- \\
-\end{array}$ \\
\hline
\end{tabular}

${ }^{*} \mathrm{p}<0.05 ;{ }^{* *} \mathrm{p}<0.01 ; * * \mathrm{p}<0.001$ (significance of risk factors).

tAbsence of this symptom in never smokers makes the point estimates of the odds ratio unreliable, which is analogous to trying to estimate the odds ratio in a two by two table when one of the cell frequencies is zero. The odds ratios are calculated from a model containing age, current smoking as a categorical variable (current smokers $v$ never smokers and other smokers $v$ never smokers), the score obtained on the reactivity scale, exposure in units of 1000 hours, and an exposure reactivity interaction term if it contributed significantly (p $<0.05$ ) to the model. 
Table 5 Odds ratios and 95\% confidence intervals (in parentheses) for 294 current smokers

\begin{tabular}{|c|c|c|c|c|}
\hline \multirow[b]{2}{*}{ Symptoms } & \multicolumn{4}{|l|}{ Risk factors } \\
\hline & 10 pack-years & $\begin{array}{l}\text { Reactivity score } \\
\text { (per unit on scale) }\end{array}$ & $\begin{array}{l}\text { Exposure } \\
\text { (per } 1000 \text { hours) }\end{array}$ & $\begin{array}{l}\text { Exposure reactivity } \dagger \\
\text { interaction }\end{array}$ \\
\hline $\begin{array}{l}\text { Wheeze apart from colds } \\
\text { Persistent wheeze } \\
\text { Dyspnoea grade } 2\end{array}$ & $\begin{array}{l}1.01(1.00-1.02) \\
1.20(0.96-1.50) \\
1.09(0.85-1.38)\end{array}$ & $\begin{array}{l}1 \cdot 11^{* *}(1.03-1.20) \\
1 \cdot 16^{* *}(1.06-1.27) \\
1.21^{* *}(1.08-1.34)\end{array}$ & $\begin{array}{l}1.02(0.97-1.06) \\
1.06^{*}(1.01-1.13) \\
0.97(0.89-1.04)\end{array}$ & $\begin{array}{l}\bar{I} \\
1.02 *(1.00-1.04)\end{array}$ \\
\hline
\end{tabular}

${ }^{*} p<0.05 ; * * p<0.01$ (significance of risk factors).

†Interaction term was retained in the model only if it contributed significantly $(p<0.05)$ (see legend table 4$)$.

1000 hours of work. This increase did not depend on the presence of a history suggesting increased airway reactivity. In addition, there was a positive interaction between exposure and reactivity in relation to the prevalence of dyspnoea.

To determine which components of the reactivity scale were most important as predictors of future respiratory complaints, further logistic regression analyses were carried out for all 537 subjects. The various items in each of the three components of the reactivity scale - namely, wheezing syndromes before employment; personal history of atopy; family history of atopy or wheezing syndromes-were entered separately to test their predictive power as independent variables. Those associated with a statistically significant (at the 5\% level) increase in risk for current wheezing syndromes were positive answers to the questions indicating the presence of wheezing syndromes before employment (see table 2). There was, however, no relation between dyspnoea grade 2 and wheezing syndromes before employment, but an increase in the risk of dyspnoea grade 2 was found in relation to a history of chronic rhinitis and less so to a personal history of urticaria $(p=0 \cdot 11)$. No other component of the reactivity scale appeared to relate significantly to the presence of either current wheezing syndromes or breathlessness.

\section{Discussion}

Cigarette smoking and an asthmatic predisposition were the major determinants of chronic respiratory symptoms in our subjects. Cough and phlegm have been consistently associated with cigarette smoking ${ }^{13}$ but the health consequences of these symptoms, even if present for a prolonged period, appear to be minor if there is no associated airways obstruction. ${ }^{14}$ By contrast, wheezing is due to narrowing of airways ${ }^{15}$ and persistent wheeze has been considered to be indicative of irreversible airways obstruction. ${ }^{16}$ The strong association found between this complaint and cigarette smoking confirms the predominant role of cigarette smoking in chronic airways obstruction in this population.
The independent role of an asthmatic $\overrightarrow{\vec{\omega}}$ predisposition-that is, a history suggesting airway $\stackrel{\circ}{\circ}$ hyperreactivity present before employment in the $\underset{\mathbb{D}}{\stackrel{D}{ }}$ trade-as a risk factor for chronic respiratory symp- $?$ toms is consistent with the Dutch hypothesis. ${ }^{3}$ It is $\vec{f}$ possible, however, that the association may in part $N$ reflect biased recall. For instance, those who wheezed 8 in early adulthood but no longer do so may recall this $ᄋ$ complaint less readily than those who still wheeze. Indeed, in the secondary analyses concerning individ- 7 ual components of the reactivity scale the best predic- $\frac{\mathbb{O}}{0}$ tor of current wheezing complaints was a history of such complaints before employment.

Recall bias is, however, unlikely to explain the $\vec{\bullet}$ relation between an asthmatic predisposition and dys- $\stackrel{\infty}{v}$ pnoea, since the components of the reactivity scale which best predicted this symptom were chronic rht: nitis and urticaria. Dyspnoea derives its importanee from the functional impairment which it implies. The lack of an association between this symptom and cigarette smoking is similar to the findings reported in 8 asbestos miners and millers ${ }^{17}$ in whom chronic cough $\overrightarrow{\overrightarrow{0}}$ and phlegm were related to cigarette smoking 3 whereas the prevalence of dyspnoea increased with increasing dust exposure. This led the authors to conclude that breathlessness was most likely due to early asbestosis. This apparently does not apply, however, $\frac{1}{\exists}$ in the present population (from which cases with asbestosis were excluded) in which an asthmatic pre- 3 . disposition was related to the prevalence of breath- $\bar{\theta}$ lessness. It is difficult to conceive of an asthmatic predisposition as a risk factor for parenchymal lung 0 disease and it appears likely therefore that dyspnoea grade 2 was a symptom of chronic airway abnormal-o ity in our subjects.

No independent effect of workplace exposures م could be identified in the population as a whole. This $N$ finding does not, however, absolve the dust exposure N in question from contributing to the presence of ${ }_{\sigma}^{\omega}$ chronic respiratory symptoms for two important reasons. Firstly, we only questioned current workers and $\stackrel{\circ}{\circ}$ thereby excluded from consideration those no longer $\stackrel{\mathbb{Q}}{\rightarrow}$ working who may well have the severest symptoms ? and possibly also have had the most intense exposure. 
This is supported by the age distribution of the subjects. There are relatively few workers over 50 , which suggests that early retirement from the trade is not unusual. Secondly, the only measure of exposure available was crude, only taking into account duration not intensity of exposure; even the calculation of duration of exposure involved certain assumptions for those who worked before 1963. These inaccuracies in the assessment of exposure would thus be likely to result in the attenuation rather than the exaggeration of any association between exposure and symptoms. ${ }^{1819}$ Despite this, we were able to show an increase in the prevalence of persistent wheezing in relation to increasing duration of exposure in smokers. Independently of smoking habits, subjects with evidence of an asthmatic predisposition were also susceptible to the effects of a dusty work environment as evidenced by a small but statistically significant positive interaction between the reactivity score and exposure as predictors of the complaints of wheeze and dyspnoea.

A relation between the occurrence of acute respiratory symptoms at work with certain occupational exposures and the development of subsequent chronic respiratory abnormality has been postulated for cotton $^{20}$ and grain dust exposures. ${ }^{21}$ It is of interest, therefore, that the primary determinant of the acute reactions to exposure at work reported by the insulation workers studied here was an asthmatic predisposition before exposure, suggesting again that subjects with these particular individual characteristics are at increased risk of developing chronic airway dysfunction.

The finding that acute symptoms at work related to exposure is also in keeping with the results of a previous study on chrysotile miners and millers in which symptoms suggesting increased airway reactivity (ever wheeze, wheezing with shortness of breath, and chest affected by the weather) were related to the level of dust exposure. ${ }^{22}$ In that study, in which the effect of exposure profiles was examined, airway reactivity was shown to be related to both early as well as recent dust levels, findings consistent with the possibility that heavy exposure early in a man's service contributes to the development or maintenance, or both, of increased levels of airway reactivity. Though no exposure levels were available for the present study, they were almost certainly higher in the early 1960 s than more recently even if exposure to high levels was intermittent. Both studies point to the need for more research into the effects of exposure to dusty environments (including those contaminated by asbestos) on the responsiveness of airways.

We thank Local 58 of the International Association of Heat and Frost Insulators and Asbestos Workers and all its members for their enthusiastic participation.
Requests for reprints to: Dr Pierre Ernst, Respiratory Division, 1650 Cedar Avenue, Montreal, Quebec, Canada H3G 1A4.

\section{References}

1 US Department of Health and Human Services. The health consequences of smoking: chronic obstructive lung disease. A report of the Surgeon General. Arlington: DHHS, 1984. (PHS 84-50205.)

2 Fletcher C, Peto R, Tinker C, Speizer FE. The natural history of chronic bronchitis and emphysema. Oxford: Oxford University Press, 1976.

3 Weiss ST, Speizer FE. Increased levels of airways responsiveness as a risk factor for development of chronic obstructive lung disease. What are the issues? Chest 1984;86:3-4.

4 Becklake MR. Chronic airflow limitation: its relationship to work in dusty occupations. Chest $1985 ; 85: 514-8$.

5 Seaton A. Coal and the lung. Thorax 1983;38:241-3.

6 Becklake MR, Ernst P. Asbestos and airway responses. In: Gee JBL, ed. Occupational lung disease. New York: ChurchillLivingstone, 1984:25-50.

7 Fournier-Massey G, Becklake MR. Pulmonary function profiles in Quebec asbestos workers. Bull Physiopathol Respir 1975;11:429-45.

8 Begin R, Cantin A, Berthiaume Y, Boileau R, Peloquin S, Masse S. Airway function in lifetime non-smoking older asbestos workers. Am J Med 1983;75:631-8.

9 Ferris BG. Epidemiology standardization project. Am Rev Respir Dis 1978;118:1-120.

10 Cockcroft DW, Berscheid BA, Murdock KY. Unimodal distribution of bronchial responsiveness to inhaled histamine in a random human population. Chest 1983;83:751-4.

11 Baker RJ, Nelder JA. The GLIM system. Release 3. Generalized linear interactive modelling. Oxford: Royal Statistical Society, 1978.

12 SAS User's Guide: Statistics. Cary, NC: SAS Institute Inc, 1982.

13 Burrows B, Lebowitz MD. Characteristics of chronic bronchitis in a warm dry region. Am Rev Respir Dis 1975;112:365-70.

14 Peto R, Speizer FE, Cochrane AL, et al. The prevalence in adults of air-flow obstruction, but not of mucous hypersecretion, to mortality from chronic lung disease. Results from 20 years of prospective observation. Am Rev Respir Dis 1983;128: 491-500.

15 Murphy RLJ Jr, Holford SK. Basics of RD. Lung sounds. ATS News 1980;8:24-9.

16 Ferris BG Jr, Higgins ITT, Higgins MW, Peters JM, Van Ganse WF, Goldman MD. Chronic non-specific respiratory disease, Berlin, New Hampshire, 1961-7: a cross-sectional study. Am Rev Respir Dis 1971;104:232-44.

17 McDonald JC, Becklake MR, Fournier-Massey G, Rossiter CE. Respiratory symptoms in chrysotile asbestos mine and mill workers of Quebec. Arch Environ Health 1972;24:358-63.

18 Pickles $\mathrm{JH}$. Air pollution estimation error and what is does to epidemiololgical analysis. Atmospheric Environment 1982; 16:2241-5.

19 Armstrong BG, Oakes D. Effects of approximation in exposure assessments on estimates of exposure-response relationships. Scand J Work Environ Health 1982;8(suppl 1):20-3.

20 Weill H. Relations between acute and chronic occupational airway responses. In: Gee JBL, Morgan WKC, Brooks SM, eds. Occupational lung disease. New York: Raven Press, 1984:87-95.

21 Tabona M, Chan-Yeung M, Enarson D, MacLean L, Dalui E, Schulzer M. Host factors affecting longitudinal decline in lung spirometry among grain elevator workers. Chest 1984;85:782-6.

22 Copes R, Thomas D, Becklake MR. Temporal patterns of exposure and nonmalignant pulmonary abnormality in Quebec chrysotile workers. Arch Environ Health 1985;40:80-6. 